\title{
Do Atypical Food Preferences in Children with Autism Differ by Severity?
}

\author{
Prahbhjot Malhi ${ }^{1} \cdot$ Lolam Venkatesh $^{2} \cdot$ Bhavneet Bharti $^{1} \cdot$ Pratibha Singhi $^{1}$
}

Received: 7 July 2020 / Accepted: 7 October 2020 / Published online: 20 October 2020

(C) Dr. K C Chaudhuri Foundation 2020

To the Editor: There is a need to delineate some of the risk factors and correlates of feeding problems in autism, specifically whether atypical food preferences in children with autism differ by severity of autism. Fifty children with Autism spectrum disorder (ASD) (4-12 y) were enrolled from the outpatient services of a pediatric hospital. The Childhood Autism Rating Scale (CARS) was used to define severity of autism and two groups were identified: mild/moderate and severe. Feeding problems were measured by the Children's Eating Behavior Inventory (CEBI) and it yields two scores: total score and number of feeding problems [1]. The diet software was used to calculate the daily nutrient intake. The study was cleared by the Institute ethics board.

The two ASD groups were matched for age, sex, residence, education of mother, and socioeconomic status. Children with severe ASD, relative to the milder symptoms group, had significantly higher scores on the CEBI $(\mathrm{t}=4.12, P=0.0001)$ and a greater number of feeding problems $(\mathrm{t}=3.12, P=$ 0.003). Specific micro-nutrient inadequacies were found; and the severe group had lower levels of sodium $(\mathrm{t}=2.48$; $P=0.017)$, copper $(\mathrm{t}=2.73 ; P=0.009)$, iron $(\mathrm{t}=1.93, P=$ $0.05)$, and thiamin $(\mathrm{t}=2.10, P=0.041)$. Growth of children with severe ASD was more compromised and they were shorter $(\mathrm{t}=2.74, P=0.009)$ and lighter $(\mathrm{t}=2.68, P=0.01)$ relative to the mild/moderate group. Step-wise multivariate regression analysis revealed that $39.2 \%$ of the variance in

Prahbhjot Malhi

pmalhi18@hotmail.com

1 Department of Pediatrics, Post Graduate Institute of Medical Education and Research, Sector 12, Chandigarh 160012, India

2 Department of Pediatrics, Jawaharlal Institute of Postgraduate Medical Education and Research (JIPMER), Puducherry, India the total CEBI score was predicted by the CARS score and $\mathrm{z}$ weight score of the child $(\mathrm{F}=15.17, P=0.0001)$.

Findings suggest that children with severe autism had significantly greater mealtime problems and parents reported preoccupation with feeding issues, stress, and disruption of family mealtime routines $[2,3]$. Previous studies too have found that mealtime behavior problems compromise healthy eating behaviors and lead to lower quality diets, malnutrition, and poor growth parameters [3-5]. Our study extends these findings and suggests that there is variability even among the ASD group, and the clinically severe ASD cases may be at a higher risk for experiencing feeding and nutritional inadequacies leading to growth failure. There is a need to increase food variety and intake adequacy to promote healthy eating and growth among children with autism.

\section{Compliance with Ethical Standards}

Conflict of Interest None.

\section{References}

1. Archer LA, Rosenbaum PL, Streiner DL. The children's eating behavior inventory. J Pediatr Psychol. 1991;16:629-42.

2. Malhi P, Venkatesh L, Bharti B, Singhi P. Feeding problems and nutrient intake in children with and without autism: a comparative study. Indian J Pediatr. 2017;84:283-8.

3. Johnson CR, Turner K, Stewart PA, et al. Relationships between feeding problems, behavioral characteristics and nutritional quality in children with ASD. J Autism Dev Disord. 2014;44:2175-84.

4. Sharp WG, Postorino V, McCracken CE, et al. Dietary intake, nutrient status, and growth parameters in children with autism spectrum disorder and severe food selectivity: an electronic medical record review. J Acad Nutr Diet. 2018;118:1943-50.

5. Peverill S, Smith IM, Duku E, et al. Developmental trajectories of feeding problems in children with autism spectrum disorder. J Pediatr Psychol. 2019;44:988-98.

Publisher's Note Springer Nature remains neutral with regard to jurisdictional claims in published maps and institutional affiliations. 